\title{
CONCENTRIC LEFT VENTRICULAR HYPERTROPHY LATE AFTER AORTIC VALVE REPLACEMENT IN TAKAYASU'S ARTERITIS
}

Yasushi Terada, MD, ${ }^{\mathrm{a}}$ Toshio Mitsui, MD, ${ }^{\mathrm{a}}$ Yasuhiko Wanibuchi, MD, ${ }^{\mathrm{b}}$ Ikutarou Kigawa, MD, ${ }^{\mathrm{b}}$

Sachito Fukuda, MD, ${ }^{\mathrm{b}}$ Tomoaki Jikuya, MD, ${ }^{\mathrm{a}}$ and Kenji Okamura, MD, ${ }^{\mathrm{a}}$ Tsukuba and Tokyo, Japan

From the Department of Cardiovascular Surgery, Institute of Clinical Medicine, University of Tsukuba, ${ }^{\text {a }}$ Tsukuba, Japan, and the Department of Cardiovascular Surgery, Mitsui Memorial Hospital, ${ }^{\text {b }}$ Tokyo, Japan.

Received for publication August 5, 1997; accepted for publication Sept. 8, 1997.

Address for reprints: Yasushi Terada, MD, Department of Cardiovascular Surgery, Institute of Clinical Medicine, University of Tsukuba, Tsukuba-shi, Ibaraki-ken 305, Japan.

J Thorac Cardiovasc Surg 1998;115:724-5

Copyright (C) 1998 by Mosby, Inc.

$0022-5223 / 98 \$ 5.00+0 \quad \mathbf{1 2 / 5 4} / \mathbf{8 5 9 9 4}$
The clinical features of aortic regurgitation in Takayasu's arteritis differ from those in other rheumatic or degenerative valve diseases. In addition to the inflammatory vascular lesions, ventricular arrhythmias occur more often, and concentric left ventricular hypertrophy occurs even in the presence of aortic regurgitation. ${ }^{1}$ The geometry of the left ventricle after aortic valve replacement (AVR) for Takayasu's arteritis is unknown and was the focus of this study.

Patients and methods. Until 1997, 10 female and three male patients aged 34 to 68 years (mean age 49 years) underwent AVR for aortic regurgitation in Takayasu's arteritis. There were multiple vascular lesions. AVR was 
Table I. Preoperative and postoperative parameters

\begin{tabular}{lccc}
\hline & $\begin{array}{c}\text { Preoperative } \\
\text { measurements }\end{array}$ & $\begin{array}{c}\text { Postoperative } \\
\text { measurements }\end{array}$ & $\begin{array}{c}p \\
\text { Value }\end{array}$ \\
\hline $\begin{array}{l}\text { LVEDD (mm) } \\
\text { LV end-systolic }\end{array}$ & $64.7 \pm 11.6$ & $45.0 \pm 8.2$ & $p<0.01$ \\
$\quad$ dimension (mm) & & & \\
LV fractional & $31.6 \pm 6.5$ & $31.8 \pm 14.2$ & $\mathrm{NS}$ \\
$\quad$ shortening (\%) & & $31.2 \pm 11.4$ & $p<0.01$ \\
$\begin{array}{l}\text { LVWT (mm) } \\
\text { LV mass index } \\
\quad\left(\mathrm{gm} / \mathrm{m}^{2}\right)\end{array}$ & $22.4 \pm 3.8$ & $25.8 \pm 2.2$ & $\mathrm{p}<0.05$ \\
CHR & $0.28 \pm 0.07$ & $0.37 \pm 0.05$ & $\mathrm{p}<0.01$ \\
\hline
\end{tabular}

$L V$, Left ventricular, $W T$, wall thickness; $N S$, not significant.

performed in 10 patients, aortic root reconstruction was performed in one, AVR plus graft replacement of the dilated ascending aorta was performed in one, and AVR plus mitral valve replacement was performed in one. The prostheses used included four $27 \mathrm{~mm}$, six $25 \mathrm{~mm}$, and three $23 \mathrm{~mm}$ mechanical valves. No vascular reconstruction was done simultaneously. There was one in-hospital death, and one patient died of pneumonia 2 months after the operation. The remaining 11 patients were included in the study.

Standard M-mode and two-dimensional echocardiograms and color Doppler echocardiograms were obtained a mean of 50.6 months after AVR (range 2 to 180 months). Left ventricular mass was calculated by the American Society of Echocardiography cube method. Concentric hypertrophic ratio (CHR) was calculated as follows ${ }^{2}$ :

$$
\mathrm{CHR}=\mathrm{WT} /(\mathrm{LVEDD}+\mathrm{WT})
$$

where $W T$ is wall thickness (interventricular septal thickness plus left ventricular posterior wall thickness) and $L V E D D$ is left ventricular end-diastolic dimension.

Results. A small peri-prosthetic valve leakage was seen in one patient. There was a significant reduction in left ventricular dimensions $(p<0.01)$ and left ventricular mass index $(p<0.01)$ after the operation. The left ventricular wall thickened $(p<0.05)$ and the CHR increased $(p<0.01)$ significantly after the operation (Table I, Fig. 1).

Discussion. Good recovery of the clinical condition and cardiac function after AVR has been reported for patients with Takayasu's arteritis. ${ }^{3}$ Our study showed an increase in the left ventricular wall thickness despite decreased ventricular dimensions at 50.6 months' mean follow-up.

Our patients showed a $40 \%$ regression of left ventricular mass after AVR, which may be a result of the left ventricular volume unloading. AVR was accompanied by at least partial regression of left ventricular hypertrophy. ${ }^{4}$ About $20 \%$ to $40 \%$ left ventricular mass reductions are reported in the literature for mean follow-up times ranging from 1 month to 1 year.

Despite left ventricular mass regression, the left ventricle exhibited concentric hypertrophy. The mechanism is unclear; however, we speculate that long-standing pressure overload may account for this geometric change.

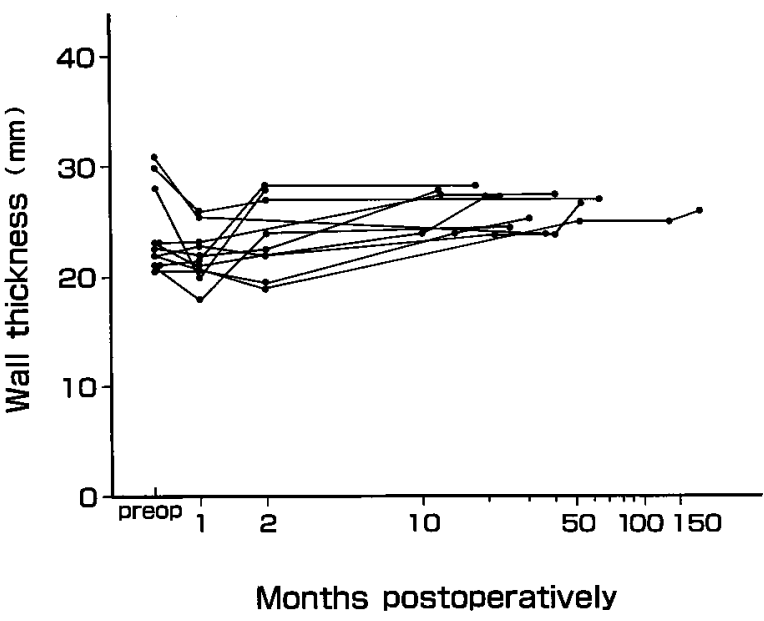

Fig. 1. Left ventricular wall thickness after operation. Time after the operation is presented as the logarithm of time (in months).

Preoperative catheterization revealed the pressure in the ascending aorta to be $160.1 \pm 27.7 \mathrm{~mm} \mathrm{Hg}$ (range 120 to $210 \mathrm{~mm} \mathrm{Hg}$ ). The value of peripheral blood pressure is incorrect, because the aorta and its branches are affected by an inflammatory process in some patients. We have no data to support this conjecture, but inflammatorily thickened aorta may produce a low wall elasticity and decrease the Windkessel effect, resulting in high systolic pressure at the aortic root. Control of the inflammation was poor in nine of 11 patients after the operation, although five of those patients had received prednisolone. Improvement of stenosed arteries and a decrease in the thickening of the arterial wall ${ }^{5}$ during corticosteroid therapy have been reported. Control of hypertension and inflammation may be necessary to obtain good long-term results.

In summary, AVR released the left ventricle from volume overload in patients with Takayasu's arteritis. However, concentric left ventricular hypertrophy occurred at 50.6 months' mean follow-up.

\section{REFERENCES}

1. Hashimoto Y, Oniki T, Kaneko E, et al. Concentric left ventricular hypertrophy in patients with Takayasu arteritis. Angiology 1993;44:883-8.

2. Hashimoto Y, Numano F, Oniki T, et al. Left ventricular geometry in Takayasu arteritis complicated by severe aortic regurgitation. Cardiology 1992;80:180-3.

3. Ohteki H, Itoh T, Natsuaki M, et al. Aortic valve replacement for Takayasu's arteritis. J Thorac Cardiovasc Surg 1992;104: 482-6.

4. Monrad ES, Hess OM, Tomoyuki M, Nonogi H, Corin WJ, Krayenbuehl HP. Time course of regression of left ventricular hypertrophy after aortic valve replacement. Circulation 1988; 77:1345-55.

5. Verlato F, Salmistraro G, Avruscio GP, Signorini GP. Takayasu's arteritis: anatomic change before and after steroid therapy evaluated by angiography and echo-Doppler colorflow. Int Angiol 1992;11:233-6. 